\title{
PENINGKATKAN MOTIVASI INTRINSIK DAN EKSTRINSIK MELALUI SPORT EDUCATION MODEL PADA PERMAINAN BOLABASKET
}

\author{
Rizki Burstiando \\ Penjaskesrek Universitas Nusantara PGRI Kediri \\ rizkiburst@unpkediri.ac.id
}

\begin{abstract}
Abstrak
Penelitian ini bertujuan untuk mengetahui besarnya peningkatan intrinsik motivation dan ekstrinsik motivation pada siswa yang mengikuti pembelajaran permainan bola basket dengan menggunakan sport education model. Hal ini dirasa penting karena (Hastie \& Trost, 2002; Siedentop et al, 2004; Perlman, 2010) dalam Perlman (2012) menyatakan salah satu model instruksi yang telah selaras dengan elemen kunci design kurikulum yang baik dan berpengaruh positif mengatasi siswa dengan kecenderungan kurang motivasi adalah sport education model. Namun penelti merasa bahwa belum ada kepastian jenis motivasi mana yang lebih meningkat dari kedua jenis motivasi tersebut. Penelitian menggunakan design one group pretest-posttest dimana data diambil dari data sekunder Burstiando(2015). Instrumen penelitian menggunakan intrument yang dikembangkan oleh Standage dkk, 2005. Treatment penelitian dilakukan selama 10 pertemuan pada kedua kelompok dengan waktu efektif 65 menit per pertemuan. Analisis data menggunakan aplikasi Ms. Excel dan SPSS 20.0 untuk mempermudah ketepatan analisis. Hasil dari penelitian ini adalah Sport Education Model secara signifikan meningkatkan motivation baik secara intrinsik maupun ekstrinsik siswa pada permainan bola basket.
\end{abstract}

\section{PENDAHULUAN}

\section{Konsep Permainan Bolabasket}

Bolabasket merupakan salah satu permainan yang digemari oleh masyarakat di Indonesia, khususnya para pelajar. Meskipun pamor olahraga ini masih di bawah permainan sepakbola dan bolavoli secara umum. Bola basket merupakan salah satu dari sekian banyak jenis permainan yang termasuk dalam katagori bola besar. Permainan bola basket sendiri bukanlah permainan asli asal indonesia, konon ceritanya permainan ini dulunya dibawa oleh para pedagang pendatang dari Cina. Tak aneh jika dalam perkembangannya olahraga ini banyak diminati murid-murid sekolah Cina di Indonesia, meskipun penemu olahraga ini sebenarnya adalah Naismth pada tahun 1891 dari Amerika. 
Permainan bola basket menurut Sucipto dkk (2010, hlm 4) adalah permainan yang dimainkan dengan tangan, dalam arti bola selalu dimainkan dari tangan ke tangan pemain dalam satu regu. Dalam memainkan bola basket seseorang dituntut untuk selalu bergerak dengan cepat dan akurat pada posisinya masing-masing. Beberapa tehnik dasar dalam permainan bola basket yang terdapat dalam pembelajaran bola basket dikutip dalam buku siswa kurikulum 2013 antara lain :

1. Prinsip dasar melempar dan menangkap bola (passing and catching)

2. Prinsip menggiring bola (dribling)

3. Prinsip menembak bola (shooting)

4. Prinsip gerakan berporos (pivot)

5. Prinsip Lay Up

6. Prinsip merayah (rebound).

Taktik dalam permainan bola basket dapat dikelompokkan ke dalam taktik serangan dan taktik pertahanan yang biasa disebut defense dan offense. Menurut Sucipto dkk (2010, hlm. 54) menerangkan bahwa taktik serangan adalah siasat atau akal para pemain yang digunakan baik secara individual maupun kelompok untuk menguasai bola supaya lawan tidak dapat memainkan bola, atau kesulitan memainkan bola sehingga tidak dapat melakukan serangan secara sempurna. Sedangkan taktik bertahan adalah suatu siasat yang dilakukan oleh perorangan atau kelompok kepada lawan dengan maksud menahan serangan lawan agar lawan tidak dapat mencetak angka.

Peraturan dalam permainan bola basket di Indonesia menganut aturan yang ada dalam FIBA (International Amateur Basketball Federation). Namun dalam penjasorkes yang menggunakan permainan bolabasket tersebut sebagai salah satu materi dalam kurikulumnya tentu saja aturan-aturan tersebut tidak serta merta diterapkan kepada para siswa. Mengingat kondisi siswa sesuai tahap perkembangannya maka biasanya para guru melakukan modivikasi permainan sesuai kondisi perkembangan siswa, ketersediaan alat, alokasi waktu dan lain-lain.

Tujuan penjasorkes yang hendak dicapai tertuang dalam kurikulum yang diatur oleh pemerintah. Pada jenjang SMP/MTs tujuan penjasorkes tertuang dalam Permendikbud nomer 68 tahun 2013 tentang kerangka dasar dan struktur kurikulum SMP-MTs yang diwujudkan dalam bentuk kompetensi inti (KI) dan diturunkan menjadi kompetensi dasar (KD). KI terdiri dari 4 aspek utama yaitu spiritual, sosial, pengetahuan, dan keterampilan. Untuk mencapai 
$\mathrm{KI}$ tersebut maka harus mencapai KD yang merupakan turunan dari KI. Salah satu KD untuk penjasorkes siswa kelas VII yaitu memahami konsep ketrampilan gerak fundamental permainan bola besar dan juga mempraktikkan teknik dasar permainan bola besar dengan menekankan gerak dasar fundamental. Menurut Sukintaka (1992) pengelompokan berdasarkan pembedaan di lembaga pendidikan permainan yang menggunakan bola besar antara lain sepakbola, bolavoli, bolabasket, dan bola tangan.

Sebagaimana kita ketahui umumnya di daerah pedesaan jarang kita ketemukan adanya lapangan basket. Lapangan basket ada sebatas di sekolahsekolahan saja. Hal ini menyebabkan ketika siswa mendapatkan pembelajaran bola basket pada saat pembelajaran penjasorkes kurang memahami akan permainan ini. Mereka cenderung lebih memilih ke permainan-permainan yang sering mereka jumpai di lingkungan mereka sehari-hari seperti sepak bola atau bola voli. Sedangkan dengan tuntutan KD yang ada, siswa dituntut untuk menguasai ketrampilan bolabasket.

Ketertarikan siswa terhadap pembelajaran berhubungan dengan motivasi siswa mengikuti pembelajaran. Dengan siswa tertarik mengindikasikan bahwa siswa tersebut memiliki motivasi dalam mengikuti pembelajaran. Untuk itu perlu dimanipulasi faktor yang mempengaruhi motivasi siswa untuk membuat siswa tertarik dalam mengikuti pembelajaran bolabasket. Menurut Morgan (1990) dalam Mubiar (2011) beberapa faktor yang mempengaruhi motivasi yaitu: (1) tingkah laku dan karakteristik model; (2) harapan orang tua; (3) Lingkungan; (4) Penekanan kemandirian; (5) Praktik pengasuhan anak.

Dari faktor di atas maka dapat dijelaskan bahwa lingkungan sekolah merupakan faktor yang dapat dirubah untuk menumbuhkan motivasi siswa dalam mengikuti pembelajaran permainan bolabasket karena bolabasket jarang dimainkan oleh masyarakat di desa-desa. Manipulasi lingkungan sekolah merupakan usaha untuk meningkatkan motivasi siswa agar pembelajaran bola basket menjadi menarik untuk dipelajari oleh siswa. Akan tetapi pelaksanaan pembelajaran di sekolah saat ini masih belum dapat meningkatkan motivasi siswa untuk pembelajaran permainan bola basket. Pembelajaran di sekolah masih cenderung menggunakan pembelajaran tradisional dengan menekankan pada penguasaan tehnik dasar, dan berorientasi pada ketrampilan tehnik bermain pada kecabangan olahraga. Berdasarkan penjelasan di atas maka 
penting untuk meningkatkan motivasi siswa agar tertarik bermain bola basket, dengan semakin tingginya motivasi bermain tersebut nantinya akan mempermudah siswa untuk belajar ketrampilan-ketrampilan dalam bola basket. Menurut Stanley (1977) we learn when we need to learn, we learn best when we want to learn. Siswa akan belajar dengan baik apabila siswa telah benarbenar ingin untuk mempelajari hal tersebut dalam hal ini permainan bola basket. Tugas guru adalah membuat siswa aktif, menilai dengan teliti kesalahan yang dilakukan oleh siswa, dan membantu untuk menemukan jalan keluar bagi siswa tersebut untuk memecahkan masalahnya sendiri.

\section{Konsep Motivasi}

Motivasi sebagai proses psikologi adalah refleksi kekuatan interaksi antara kognisi, pengalaman dan kebutuhan. Menurut Loehr (dalam Komarudin, 2013, hlm. 25) menjelaskan motivasi adalah energi yang membuat segalanya berjalan. Lebih lanjut Loehr (dalam Komarudin, 2013, hlm. 25) menjelaskan dengan tegas bahwa ketika kamu benar-benar kehilangan tujuanmu dan ketika kamu tidak lagi menemukan sebuah alasan yang dirasa penting. Maka kamu telah selesai sebagai atlet yang berkompetisi. Sedangkan menurut Komarudin (2013, hlm. 24) mendefinisikan motivasi sebagai dorongan yang berasal dari dalam atau dari luar individu untuk melakukan suatu aktifitas yang bisa menjamin kelangsungan aktifitas tersebut, serta dapat menentukan arah, haluan serta besaran upaya yang dikerahkan untuk melakukan aktivitas sehingga dapat mencapai tujuan yang telah ditetapkan. Menurut Noumanis, dkk (2011, hlm. 3) menyatakan Self determination theory secara luas digunakan untuk mempelajari motivasi pada konteks pendidikan jasmani. Selain itu. Pendapat lain adalah dari (Deci, 2000 dalam Lindsey dkk (2015, hlm. 96) menyatakan bahwa salah satu teori yang mendukung dimensi motivasi dalam pendidikan jasmani adalah self determination theory. Deci dan Ryan dalam Standage, dkk (2005, hlm. 412) menyatakan bahwa beberapa tipe motivasi yang berbeda mendasari self determination tersebut. Dari level tertinggi hingga paling rendah dari self determined motivation itu adalah intrinsik motivation, ekstrinsik motivation, dan amotivated. Deci dan Ryan (1985) dikutip dari Rink (1993, hlm. 190) menyatakan dua tipe situasi yang membuat orang bermotivasi intrinsik. Pertama situasi ketika seseorang merasa bosan dan memutuskan untuk berstimulasi. Dan kedua adalah situasi keinginan melibatkan diri untuk 
tertantang dan mengurangi ketidaksesuaian (keinginan untuk tidak melakukannya bersama-sama). Sesuai pengalaman keduanya menarik dan cukup sulit untuk menjadi tantangan yang dapat dilakukan. Standage, dkk (2005, hlm. 412) mengatakan bahwa intrinsically motivated student would participate in PE because of feelings of satisfaction and pleasure that arise directly from the various activities embraced by the PE curriculum. Lebih jauh lagi (Deci, 1971) dalam Rink (1993, hlm. 192) menyatakan yang dimaksud dengan intrinsik motivation adalah bahwa keikutsertaan untuk mereka sendiri, dengan kata lain untuk kesenangan dan kepuasan hati dari keinginan mereka sendiri. Sebagai contoh seorang siswa yang berkeinginan mengikuti pembelajaran penjas karena memang siswa tersebut mencapai kepuasan ketika mengikuti pembelajaran penjas.

Standage dkk (2005, hal 412) menambahkan bahwa motivasi ekstrinsik meliputi integrated regulation, identified regulation, introjected regulation, external regulation. Berikut secara ringkas mengenai konsep tersebut:

a. Integrated regulation

Tipe motivasi ini adalah lebih sering ditemui pada seorang yang sudah dewasa dari pada anak-anak. Sesuai dengan pendapat (Deci \& Ryan, 2000; Vallerand, 1997) dalam Standage dkk (2005, hlm. 413) menyatakan bahwa This type of motivation is more often encountered among adults rather than children, as younger populations may be too young to have experienced or achieved a sense of integration within their self. Jadi tipe motivasi ini lebih sering ditemui pada orang dewasa dari pada anak-anak, sebagai populasi yang masih muda mungkin terlalu muda untuk memperoleh pengalaman atau capaian pemahaman untuk pengintegrasian dalam diri mereka. Oleh karena itu pada penelitian ini tidak ikut dicantumkan untuk dikaji. Karena pada populasi yang akan dijadikan penelitian di sini dirasa masih terlalu muda.

b. Identified regulation

Menurut Deci \& Ryan (1985) dalam Standage, dkk (2005, hlm. 413) menyatakan Identified regulation refers to a relatively autonomous regulatory style characterized by the acceptance of a regulation as one's own, jadi identified regulation berkenaan pada secara sadar menjalankan reguasi oleh karena menerima aturan sebagai bagian dari dirinya. 
Identified regulation merupakan melakukan sebuah keadaan yang mana keadaan tersebut telah diterima oleh dirinya. Pendapat lain Guay, Robert \& Celine (2000) dalam Standage dkk (2005, hlm 413. ) menyatakan bahwa Identified regulation terjadi ketika tingkah laku karena rasa menghargai dan menghormati apa yag telah ditentukan oleh orang lain, meskipun demikian tetap saja dikatakan extrinsik motivation karena aktivitas tidak dilakukan untuk diri sendiri namun karena alasan lain. Selain itu Ntoumanis dkk (2011, hlm 4) menyatakan bahwa identified regulation berhubungan pada mengikuti pada sebuah aktifitas karena sebuah keuntungan yang didapat. Sebagai contohnya adalah seorang siswa yang mengikuti pembelajaran penjasorkes karena dia merasa akan sehat jika dia mengikuti pelajaran penjasorkes dengan baik "saya dapat hidup sehat karena mengikuti penjas", hal ini dikatagorikan sebagai Identified regulation

\section{c. Introjected regulation}

Introjected regulation merupakan bentuk motivasi karena melakukan aktivitas karena keinginan dirinya namun lebih disebabkan karena dia merasa salah atau sebab lain yang mengharuskan dia untuk melakukan tersebut. Ryan \& Deci (2002) dalam Standage dkk (2005, hlm. 413) menyatakan introjected regulation merupakan bentuk lain dari extrinsik motivation dimana terbentuk oleh seseorang karena adanya pengaruh dari luar yang diterima oleh individu tersebut. Selain itu Ntoumanis dkk (2011, hlm. 4) menyatakan bahwa introjected regulation berhubungan dengan melakukan suatu aktifitas karena tekanan dari dalam seperti merasa bersalah, rasa malu atau ego. Sebagai contohnya adalah ketika seorang siswa yang mengikuti ekstrakulikuler bukan karena dia ingin, tetapi karena dia merasa harus melakukannya, dia merasa inilah yang dilakukan oleh seorang siswa yang baik ( merasa bersalah).

\section{Konsep Sport Education Model}

Salah satu model instruksi yang telah selaras dengan elemen kunci design kurikulum yang baik dan berpengaruh positif mengatasi siswa dengan kecenderungan kurang motivasi adalah sport education model (Hastie \& Trost, 2002; Siedentop et al, 2004; Perlman, 2010) dalam Perlman (2012). Sport education model atau apabila dibahasa indonesiakan berarti model pendidikan 
olahraga merupakan model yang mengarah pendekatan teknik dan bermain dengan peraturan yang sebenarnya. Model ini lebih mengarahkan siswa kepada arah prestasi yang diciptakan melalui suatu kompetisi antara siswa. Pencetus sport education model ini, Siedentop, secara ringkas memperuntukkan model ini untuk meningkatkan kecakapan, pemahaman, dan antusias sport persons (siswa) (Siedentop) dalam Metzler (2000).

Untuk memberikan identitas yang jelas pada SEM, Siedentop (1994) dalam Metzler (2000) mengungkapkan bahwa terdapat 6 ciri-ciri kunci SEM sebagai berikut:

1. Musim (musim kegiatan): SEM menggunakan musim, karena musim memenuhi 1 periode waktu yang lebih lama (latihan, pra musim, musim reguler, akhir musim).

2. Afiliasi tim: siswa menjadi anggota tim yang sama selama 1 musim penuh. Hal ini memberi banyak pengaruh dan tujuan pengembangan sosial. Mereka diberi kesempatan untuk bekerja untuk tujuan bersama, mengalami sukses dan gagal sebagai tim.

3. Kompetisi formal: mereka dapat memodifikasi aturan permainan yang mendukung kejujuran dan partisipasi yang lebih baik. Jadwal kompetisi formal memungkinkan setiap tim membuat keputusan musim jangka pendek dan jangka panjang.

4. Puncak kegiatan: musim berakhir dengan acara puncak yang harus meriah dan memungkinkan melibatkan semua siswa.

5. Pencatatan hasil: penilaian terhadap pembelajaran siswa dengan membuat rekor publik yang dapat digunakan pelatih dan tim untuk menganalisa kekuatan tim sendiri dan lawan.

6. Festival: venue permainan penuh warna dan didekorasi dengan spanduk atau banner. Guru-guru pendor berusaha membuat musim kompetisi semeriah mungkin.

\section{Kerangka Berfikir}

Dalam hal pembelajaran tentu motivasi siswa dalam mengikuti pelajaran dipengaruhi oleh kedua jenis motivasi tersebut yaitu intrinsik dan ekstrinsik, bisa jadi siswa tersebut memang termotivasi untuk mengikuti pembelajaran karena dorongan dirinya sendiri, karna dia menyukai aktivitas penjasorkes yang dilakukan atau dorongan dari luar misalnya karena takut dimarahi oleh gurunya 
atau karena ingin terlihat bagus oleh teman-temannya. Motivasi ini juga yang nantinya mempengaruhi kegiatan belajar mereka bisa dijadi siswa yang memang memiliki motivasi intrrinsik yang kuat tidak akan menunggu perintah dari gurunya untuk aktif bergerak. Sedangkan siswa yang hanya melakukan instruksi dari gurunya akan diam dan menunggu bila disuruh. Hal ini pula dimungkinkan akan mempengaruhi hasil mereka untuk belajar.

\section{METODE}

Desain penelitian ini menggunakan desain quasi ekperimen tanpa adanya kelompok kontrol. Dengan lebih tepatnya menggunakan one group pretest-posttest. Dimana siswa diberikan pretest dulu sebelum diberikan treatmen, yang kemudian setelah treatmen diambil nilai post-test. Data penelitian menggunakan data sekunder dari penelitian tesis yang berjudul "Pengaruh Sport Education Model terhadap Motivasi Belajar Siswa dalam Permainan Bolabasket" yang dilakukan oleh Burstiando (2015). Dimana Siswa yang berpartisipasi dalam penelitian ini sebagai subyek penelitian adalah siswa kelas VII SMP yang sebelumnya telah memperoleh pembelajaran permainan bola basket, sehingga siswa dianggap sudah pernah menjumpai dan pernah melakukan aktifitas permainan bolabasket. Selain itu keadaan lingkungan siswa berada pada lingkungan yang tidak terbiasa melakukan permainan bola basket misalnya di daerah pedesaan yang kebanyakan permainan bola besar yang lebih populer adalah permainan bola basket. Dari berbagai dasar pertimbangan tersebutlah peneliti menentukan bahwa siswa kelas VII SMP Negeri 1 Plosoklaten dijadikan sebagai partisipan. Sampel untuk penelitian ini diambil menggunakan tehnik cluster random sampling. Dari hasil cluster random sampling tersebut kemudian didapat sampel berjumlah 18 laki-laki dan 20 perempuan. Pengumpulan data dilakukan pada pre-test dan post-test menggunakan kuisioner tentang motivasi siswa berdasarkan protokol standar yang sebelumnya kuisioner tersebut telah divalidasi dan dikembangkan Standage, Duda dan Ntoumanis (2005). Mereka mengembangkan kuisioner ini untuk mengukur seluruh aspek self determination dalam konteks khusus pada olahraga dan pendidikan jasmani serta dengan populasi yang sama pada penelitian ini yaitu pada secondary school dengan rentang usia antara 11-14 tahun. Hasil uji coba kuisioner motivasi yang diadopsi dari Standage dkk (2005) 
diatas maka didapatkan hasil bahwa seluruh item "valid" untuk digunakan dalam penelitian. Namun dari kelima komponen yang ada diketahui bahwa komponen identified regulation tidak reliabel karna nilai reliabilitasnya kurang dari 0,50 yaitu hanya sebesar 0,435 .

Analisis Data

Peningkatan motivasi intrinsik dan ekstrinsik siswa diuji dengan menggunakan uji $t$-dependent untuk mengetahui peningkatan motivasi siswa pada setiap kelompok dengan membandingkan nilai pretest dan posttest. Dengan ketentuan ada peningkatan pada tiap kelompok signifikan apabila $p$ value $<0,05$.

\section{HASIL PENELITIAN}

Berdasarkan analisis data maka didapatkan deskripsi data seperti tertera pada Tabel 1.

Tabel 1. Deskripsi Data Penelitian

\begin{tabular}{ccccccc}
\hline & $\mathrm{N}$ & Minimum & Maximum & Mean & $\begin{array}{c}\text { Std. } \\
\text { Deviation }\end{array}$ & Gain \\
\hline $\begin{array}{c}\text { Preetest } \\
\text { Intrinsik } \\
\text { Motivation }\end{array}$ & 38 & 15 & 28 & 24.24 & 3.283 & \\
\cline { 1 - 1 } & & & & & & \\
$\begin{array}{c}\text { Posttest } \\
\text { Intrinsik } \\
\text { Motivation }\end{array}$ & 38 & 20 & 28 & 26.13 & 2.208 & \\
\hline $\begin{array}{c}\text { Preetest } \\
\text { External } \\
\text { Motivation }\end{array}$ & 38 & 14 & 41 & 27.29 & 8.853 & \\
\hline $\begin{array}{c}\text { Posttest } \\
\text { External } \\
\text { Motivation }\end{array}$ & 38 & 8 & 51 & 31.76 & 13.190 & \\
\hline $\begin{array}{c}\text { Valid N } \\
\text { (listwise) }\end{array}$ & 38 & & & & & \\
\hline
\end{tabular}

Dari deskripsi data tersebut dapat diketahui bahwa nilai rata-rata intrinsik motivation saat pre-test sebesar 24,24 mengalami peningkatan menjadi 26,13 ketika post-test. Sedangkan pada nilai rata-rata external motivation saat pretest sebesar 27,29 juga mengalami peningkatan menjadi 31,76 ketika post-test. Untuk melihat signifikasi peningkatan intrinsik motivation dan ekstrinsik motivation dapat dilihat pada Tabel 2. 
Tabel 2. Uji Peningkatan Intrinsik Motivation dan Ekstrinsik Motivation

\begin{tabular}{|c|c|c|c|c|c|c|c|c|}
\hline & \multicolumn{5}{|c|}{ Paired Differences } & \multirow[b]{4}{*}{$\mathrm{T}$} & \multirow[b]{4}{*}{$\mathrm{df}$} & \multirow{4}{*}{$\begin{array}{l}\text { Sig. (2- } \\
\text { tailed) }\end{array}$} \\
\hline & \multirow[b]{3}{*}{ Mean } & \multirow{3}{*}{$\begin{array}{c}\text { Std. } \\
\text { Deviation }\end{array}$} & \multirow{3}{*}{$\begin{array}{l}\text { Std. } \\
\text { Error } \\
\text { Mean }\end{array}$} & \multirow{2}{*}{\multicolumn{2}{|c|}{$\begin{array}{l}95 \% \text { Confidence } \\
\text { Interval of the } \\
\text { Difference }\end{array}$}} & & & \\
\hline & & & & & & & & \\
\hline & & & & Lower & Upper & & & \\
\hline $\begin{array}{l}\text { Posttest } \\
\text { Intrinsik } \\
\text { Motivation - } \\
\text { Pretest } \\
\text { Intrinsik } \\
\text { Motivation }\end{array}$ & 1.895 & 3.391 & .550 & .780 & 3.009 & 3.444 & 37 & .001 \\
\hline $\begin{array}{l}\text { Posttest } \\
\text { External } \\
\text { Motivation - } \\
\text { Preetest } \\
\text { External } \\
\text { Motivation }\end{array}$ & 4.474 & 11.984 & 1.944 & .535 & 8.413 & 2.301 & 37 & .027 \\
\hline
\end{tabular}

Dari hasil tersebut jika dibandingkan antara nilai pre-post pada intrinsik motivation didapat nilai $p$-value sebesar 0,001 yang berarti bahwa Sport Education Model secara signifikan meningkatkan intrinsik motivation siswa pada permainan bola basket. Sedangkan untuk nilai external motivation didapat nilai $p$-value sebesar 0,27 yang berarti bahwa Sport Education Model secara signifikan meningkatkan ekstrinsik motivation siswa pada permainan bola basket.

Suherman (2009, hlm. 124) menyatakan enam teknik memotivasi siswa belajar diantaranya (1) Teaching by Invitation, (2) Intratask Variation, (3) Task Sheet, (4) Station atau Learning Centers, (5) Child Designed Activities dan (6) Video taping. Keenam teknik tersebut terdapat dalam sport education model sebagai contoh dalam model Sport Education Model sendiri terdapat beberapa season yang menjadi kekhasan model ini. Adanya season dalam pembelajaran ini menjadi lebih variatif yang membuat siswa makin termotivasi di setiap seasonnya yang ditunjukkan dengan peningkatan nilai skor rata-rata di setiap seasonnya. Bentuk permainan dimodivikasi sesuai dengan kemampuan siswa sesuai dengan intratask variation. Terdapat lembar-lembar kerja baik sebagai pemain, rekan tim maupun petugas yang dibuat sesuai pemahaman siswa sesuai dengan teknik task sheet. Siswa memiliki kebebasan memodivikasi latihan sesuai kebutuhan timnya masing-masing dan juga merekam segala 
aktivitas pertandingan melalui kamera yang hasil akhirnya berupa artikel pertandingan yang ditulis oleh reporter yang merupakan bagian dari teknik video taping. Disamping itu terdapat beberapa siswa yang ingin untuk memperoleh gelar juara baik juara tim maupun juara individu seperti pemain terbaik dan petugas terbaik. Membuat siswa semakin giat untuk bermain dan bertugas. Dengan demikian dapat dipastikan bahwa dalam pembelajaran menggunakan Sport Education Model memberikan peningkatan motivasi belajar siswa dalam permainan bola basket. Namun jika dilihat pada selisih atau gain pada Tabel 1. Maka dapat diartikan bahwa diantara kedua tipe motivasi tersebut peningkatan yang lebih tinggi terdapat pada ektrinsik motivation dibandingkan dengan intrinsik motivation.

\section{KESIMPULAN}

Berdasarkan hasil pengolahan dan pembahasan analisis data maka dapat disimpulkan bahwa Sport Education Model secara signifikan meningkatkan intrinsik motivation siswa pada permainan bola basket, yang artinya bahwa dengan menggunakan sport education model motivasi dari dalam diri siswa semakin meningkat yang dimungkinkan akan meningkatkan hasil pembelajaran, khususnya pada permainan bolabasket. Selain itu dapat pada ekstrinsik motivation disimpulkan bahwa Sport Education Model secara signifikan meningkatkan ekstrinsik motivation siswa pada permainan bola basket, yang artinya dorongan untuk mengikuti pembelajaran dari luar diri siswa atau ekstrinsik motivation siswa mengalami peningkatan.

Namun jika dilihat dari selisih atau gain nilai rata-rata kedua jenis motivasi tersebut ekstrinsik motivation lebih tinggi peningkatannya dibandingkan dengan intrinsik motivation hal ini berarti bahwa dorongan atau motivasi siswa dari dalam dirinya tidak sebesar dorongan atau motivasi dari luar seperti perintah guru, perasaan bersalah siswa pada rekan satu timnya, maupun karena mengikuti peraturan-peraturan ang telah disepakati. Peneliti menyarankan untuk memakai model sport education model bila mana waktu pembelajaran sangat panjang, karena model pembelajaran ini mempunyai seasons yang sangat panjang, pada penelitian ini waktu yang dibutuhkan adalah selama 10 pertemuan. Sedangkan kurikulum di Indonesia hanya memberikan waktu untuk pembelajaran setiap materi seperti contoh bola basket selama 2 pertemuan 
saja yang masing-masing 40 menit. Sehingga manajemen waktu sangat dibutuhkan. Perlu adanya penelitian lebih lanjut untuk menyempurnakan penelitian ini, karena dari hasil pengolahan data dari kedua model ini ternyata peningkatan komponen motivasi yang paling meningkat adalah external regulation yang merupakan external motivation. Perlu adanya cara lain untuk lebih meningkatkan dari sisi komponen intrinsik motivation agar motivasi belajar siswa dari diri sendiri lebih kuat lagi.

\section{DAFTAR PUSTAKA}

Burstiando, R (2015). Pengaruh Sport Education Model terhadap Motivasi Siswa dalam Permainan Bolabasket. (Tesis). Sekolah Pascasarjana. Universitas Pendidikan Indonesia.

Komarudin. (2013). Psikologi Olahraga. Bandung. Remaja Rosdakarya.

Lindsey, S. dkk. (2015). Physical activity levels and motivational responses of boys and girls: A comparison of direct instruction and tactical games models of games teaching in physical education. Sage Journal : European Physical Education Review 2015, Vol. 21(1) 93-113. (on line).Tersedia di http://epe.sagepub.com/content/19/3/289.full.pdf pada 29 januari 2015

Metzler, Michael. (2000). Instructional Models for Physical Education. USA; Allyn and Bacon.

Mubiar, Agustin. (2011). Permasalahan Belajar dan Inovasi Pembelajaran. Bandung: Refika Aditama.

Ntoumanis, N. dkk. (2011). Measuring Student Motivation for Physical Education: Examining the Psychometric Properties of the Perceived Locus of Causality Questionnaire and the Situational Motivation Scale. (online). Tersedia:

http://eprints.bham.ac.uk/629/1/Ntoumanis_2011_Psychology_of_Sport.pd f. diakses pada 18 November 2014.

Perlman, Dana. (2012). The Influence of the Sport Education Model on amotivated students' in-class physical activity. (online). Tersedia: http://epe.sagepub.com/content/18/3/335 diakses pada Rabu, 16 april 2014.

Permendikbud Nomor 68 tahun 2013 tentang Kerangka Dasar dan Struktur Kurikulum SMP-MTs. 
Rink J. (1993). Teaching Physical Education for Learning. Missouri. United States of America. Mosby-Year Book, Inc.

Standage, M., Duda, J.L. \& Ntoumanis, N. (2005). A test of self-determination theory in school physical education. British Journal of Educational Psychology (2005), 75, 411-433. On line tersedia di http://sdtheory.s3.amazonaws.com/SDT/documents/2005_StandageDuda Ntoumanis_BJEP.pdf pada hari jumat, 31 Oktober 2014

Stanley, S. (1977). Physical Education a Movement Orientation. Mc Graw-Hill. Canada.

Sucipto dkk. (2010). Permainan Bola Basket. Bandung. Universitas Pendidikan Indonesia.

Suherman, A. (2009). Revitaslisasi pengajaran dalam pendidikan jasmani. Bandung. CV . Warli Bintang Artika.

Sukintaka (1992). Teori Bermain. Departemen Pendidikan dan Kebudayaan Direktorat Jendral Pendidikan Tinggi. 